\title{
Journal of Clinical Otorhinolaryngology
}

Guillaume BUIRET *

\section{Efficacy of Somnodent ${ }^{\circledR}$ Appliance Therapy in Moderate to Severe Obstructive Sleep Apnea Patients}

\section{Somnodent ${ }^{\circledR}$ OAs for Moderate to Severe OSAHS}

Guillaume Buiret ${ }^{1 *}$ and Frederic Chidiac ${ }^{1}$

Service d'ORL et de chirurgie cervicofaciale, Centre Hospitalier de Valence, 179 Boulevard du Maréchal Juin, 26953 Valence, France.

Corresponding Author: Guillaume BUIRET, Service d'ORL et de chirurgie cervicofaciale, Centre Hospitalier de Valence, 159 Boulevard du Maréchal Juin, 26953 Valence.

Received date: April 04, 2021; Accepted date: July 13, 2021; Published date: August 20, 2021

Citation: Buiret G. and Chidiac F., (2021) Efficacy of Somnodent ${ }^{\circledR}$ Appliance Therapy in Moderate to Severe Obstructive Sleep Apnea Patients. J, Clinical Otorhinolaryngology, 3(3); DOI: 10.31579/2692-9562/030

Copyright: () 2021, Guillaume Buiret, This is an open access article distributed under the Creative Commons Attribution License, which permits unrestricted use, distribution, and reproduction in any medium, provided the original work is properly cited.

\section{Abstract}

Objective: Oral appliances are one of the treatments of obstructive sleep apnea hypopnea syndrome. The main objective of the study was to determine the efficacy of the Somnodent ${ }^{\circledR}$ oral appliance on Apnea-Hypopnea Index. The secondary objective was to measure the efficacy on other oxymetric parameters and to determine its tolerance and dropout rate.

Methods: Efficacy results of the oral appliances based on the apnea hypopnea index, the oxygen desaturation index and the lower oxygen saturation reduction, appliance complications and dropout rates were retrospectively collected from 25 patients with a moderate to severe obstructive sleep apnea hypopnea syndrome treated by a Somnodent ${ }^{\circledR}$ oral appliance. The procedure was entirely performed by otolaryngologists.

Results: The AHI with OA was more significantly reduced in patients with a higher initial apnea hypopnea index and a higher initial body mass index but reduction was not related to age and not proportional to degree of mandibular advancement.

The $50 \%$-AHI reduction rate after OA was $55.6 \%$, the $\mathrm{AHI} \leq 5 / \mathrm{h}$ rate after OA was $22.2 \%$. The OA significantly reduced the mean apnea-hypopnea index $\left(-14.3 / \mathrm{h}, \mathrm{p}<10^{-5}\right)$. No patient had his AHI increased with oral appliance. One patient stopped using OA mainly because of nausea.

Conclusions: Somnodent ${ }^{\circledR}$ is an effective and well-tolerated treatment for moderate to severe obstructive sleep apnea hypopnea syndrome.

Key Words: obstructive sleep apnea, oral appliance, apnea hypopnea index

\section{Introduction}

Obstructive sleep apnea hypopnea syndrome (OSAHS) is characterized by obstruction of the Upper Airways (UA) during sleep, causing desaturation and / or arousal [1]. In its severe form, its medium- and longterm consequences are of several orders (metabolic, cerebral, behavioural, and accidental). Of these risks, vascular risk is one of the greatest. This vascular risk is both cardiological, neurological and ophthalmological [2].

In France, Oral Appliances (OAs) are one of the possible treatments of OSAHS with clinical signs such as headache, fatigue, drowsiness, nycturia, nocturnal suffocations, vascular comorbidities and road accident by falling asleep [3-7]. They are considered as a second-line treatment for severe OSAHS after refusal or discontinuation of Continuous Positive Airway Pressure (CPAP) and as a first-line treatment for moderate OSA
[8]. All OAs are anchored on teeth and aim to advance the mandible towards the maxilla. The precise mechanism of OAs action remains unclear and is probably multifactorial: increase of the caliber of the upper airway by increasing the space behind the base of tongue and the soft palate, changing of configuration of the uvula and tongue, decreasing the UA resistance [9-12] and the stretching-receptors activity in the genioglossus muscle $[11,13]$.

Different OA designs exist according to the teeth they rely on, the mechanism of advancement and/or the direction of the applied forces to advance the mandible. They are generally considered in the literature as a homogeneous group. However, considering them as a homogeneous group is debatable and very few comparisons of the efficacy and tolerance of different OA have been led [14]. 
Somnodent ${ }^{\circledR}$ is a custom-made bi-bloc propulsion OA anchored on molar teeth and with cylinders. Before comparing Somnodent ${ }^{\circledR}$ OA to another $\mathrm{OA}$, we conducted a retrospective study to evaluate its efficacy and compliance, tolerance and dropout rates in routine daily practice.

\section{Methods}

\section{Population}

The whole study took place in the ENT unit of our institution.

Every patient who received an OA between 06/01/2019 and 10/31/2020 was retrospectively included.

OA indications were:

- a severe OSAHS $(A H I \geq 30 / h)$ with clinical signs such as headaches, fatigue, drowsiness, nycturia, nocturnal suffocations, vascular comorbidities and road accident by falling asleep and refusal of or intolerance to CPAP.

- a moderate OSAHS (IAH between 15/h and 30/h) with clinical signs described above.

Patients were either directly referred to the ENT doctor by the general practitioner for a sleep exam, or by a pulmonologist, a neurologist or a cardiologist after completion of a sleep exam.

Polygraphies were performed in every patients. Interpretation was conducted using the American Association of Sleep Medicine criteria of sleep exams.

\section{Initial ENT consultation}

The initial ENT consultation, verifying the absence of OA contraindications, was fully described for another OA $[15,16]$.

After acceptance of patient's refund by the French Social Security, a dental print by alginate was performed during ENT consultation and the print was sent to the OA production site (you can see the technique on our YouTube channel: https://www.youtube.com/watch?v=d09mc7L6$\mathrm{HA} \& \mathrm{t}=37 \mathrm{~s}$.

The George Gauge bite fork process is also available on our YouTube channel: https://www.youtube.com/watch?v=Zlab2Qeh2FI.

\section{OA}

The OA design used in our unit was the Somnodent ${ }^{\circledR}$ custom-made titratable twin-block propulsion with cylinders OA manufactured by Somnomed laboratory (Beaucouzé, France). After OA ENT consultation delivery and follow up consultations:

The OA was delivered by an ENT doctor. Explanations about the set up and removal of the OA, the side effects, their management, and the maintenance of the OA were explained to the patient.Approximately two to four weeks after OA delivery, the patient was invited for the OA safety and efficacy assessment.

The multiparametric (subjective and objective) titration method [17] was performed: the OA advancement was titrated to approximately $50 \%$ of its maximum advancement when it is given to the patient. At each titration consultation (every two to four weeks), advancement was progressively increased by steps of 0.5 or 1 millimeter to ensure a maximum well-tolerated progress until improvement of clinical signs. A 1 -mm-step was the most common step. The 0.5 -mm-step was only used in case of pain induced by $\mathrm{OA}$ and its clinical ineffectiveness. The titration process can be seen on our YouTube channel: https://www.youtube.com/watch?v=OVwj0He4914\&t=2s.

Once clinical signs are amended, the patient performed polygraphy in the same place and with the same sleep specialist as the first exam (before
OA). Once the adjustment was optimized both clinically and with the sleep exam, the patient was seen regularly every six months during the first year and then on a yearly basis the following years. Follow up was conducted both by an ENT doctor in order to monitor the patient compliance, the deterioration of the $\mathrm{OA}$, and the possible recurrence of OSA signs and symptoms [18], and by a dentist, in order to monitor the oral and dental impact.

\section{Primary and secondary objectives}

The main objective of the study was to determine OA efficacy on AHI.

The secondary objectives of this study were to determine rates of:

- OA efficacy on other oxymetric parameters

- OA tolerance

- OA dropouts

\section{Primary and secondary outcomes}

The main outcome measure was the most frequently used criteria of efficacy existing in the literature:

$$
\begin{aligned}
& \circ \text { A } 50 \% \text {-AHI reduction after OA } \\
& \circ \text { A residual } \mathrm{AHI} \leq 5 / \mathrm{h} \text {. } \\
& \circ \text { A }<50 \% \text { AHI reduction and / or residual } \mathrm{AHI}>10 / \mathrm{h} \text {. }
\end{aligned}
$$

The secondary outcomes measures were:

- The impact of OA on other parameters that are vitally important and less subjectively scored than the AHI: Oxygen desaturation index (ODI), lowest oxygen saturation (LOS) and time below 90\% saturation (TB90S)

- The rates of problem of OA tolerance: not enough or too much retention, pain, gingival bleeding for example...

- The rates and causes of OA dropout.

\section{Statistical studies}

Mean comparisons were performed with Student tests and ANOVA.

Our model was built using univariate linear modeling. If necessary, multivariate linear modeling was performed with putative confounding factors.

Every test and modeling were performed with R software.

\section{Ethical consideration}

All procedures performed in studies involving human participants were in accordance with the ethical standards of the institutional and/or national research committee and with the 1964 Helsinki declaration and its later amendments or comparable ethical standards.

For this type of study, formal consent from patients or the statement of institutional review board are not required in France.

\section{Results}

\section{General data}

Twenty-seven patients ( 21 males and 6 females) received an OA between $06 / 01 / 2019$ and $12 / 31 / 2020$. The mean age was $58.9 \pm 13.9$ years. The mean Body Mass Index (BMI) was $28 \pm 5.1 \mathrm{~kg} / \mathrm{m}^{2}$. Ten patients $(37 \%)$ stopped their CPAP treatment because of they could not tolerate it and eight $(29.6 \%)$ refused it. The other characteristics of the population are reported in Table 1. The flowchart is shown in Figure 1. Twenty-two patients were finally included (21 patients with polygraphic or polysomnographic control and one patient who gave-up OA before with 
polygraphic or polysomnographic control). Five patients are waiting for their sleep exam control.
AHI at diagnosis significantly increased with age but not with the Body Mass Index (BMI) ( $\mathrm{p}=0.0387$ and 0.5621 respectively). In other words, initial AHI was significantly higher in older and but not in heavier patients.

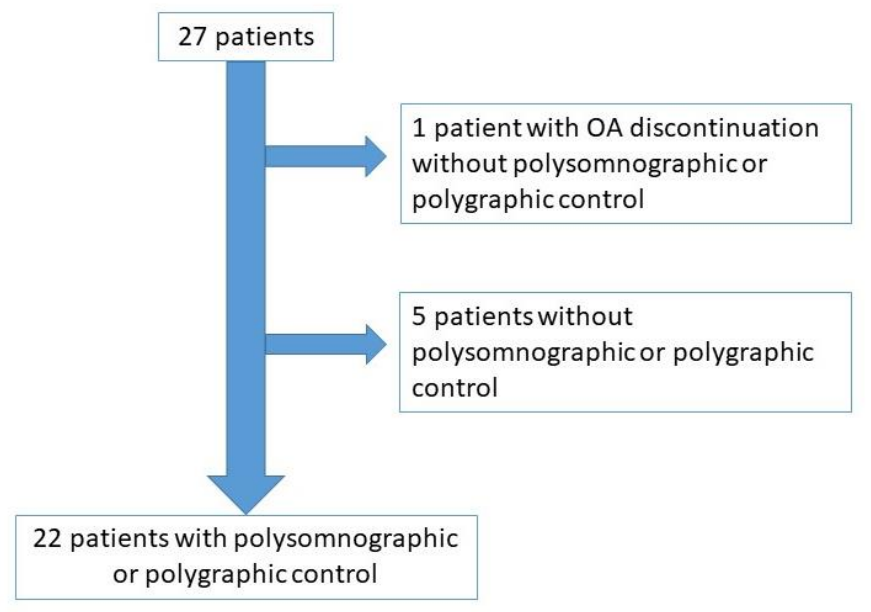

\section{Figure 1: Study flowchart}

\section{Delivery of the $O A$}

At its delivery, OA appeared ill-adapted for three patients (12\%) because of too much teeth retention leading to pain. New dental prints were immediately performed to redo another OA.

A

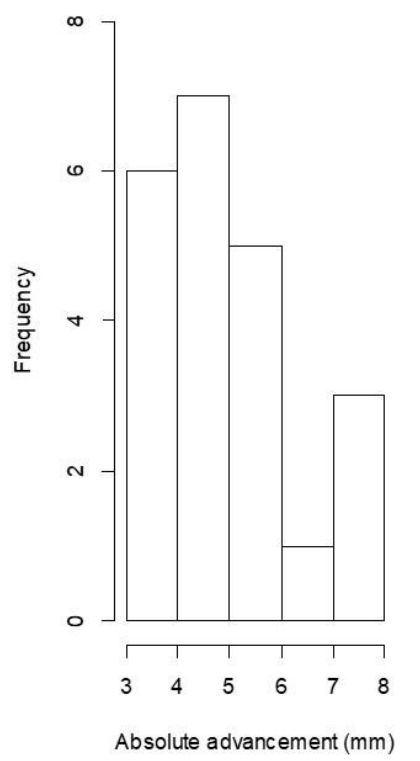

As shown in Figure 1, five patients $(18.5 \%)$ did not undergo their sleep exam control at the time of the redaction of this article.

The figure 2 presents variability of the absolute and relative advancements applied thanks to the OA.

B

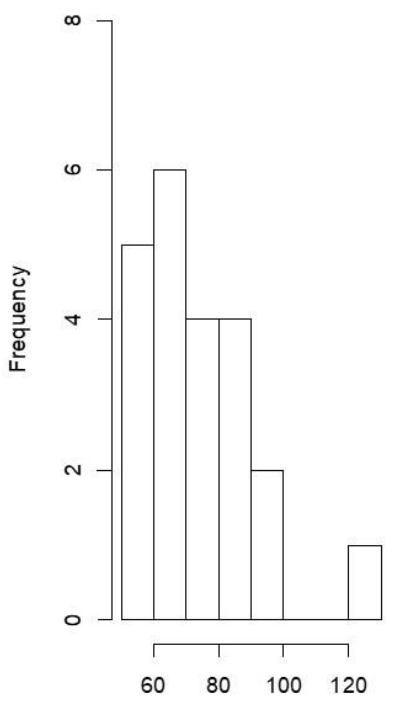

Relative advancement (\%)

Figure 2: Absolute advancement $(A)$ and relative advancement at last consultation $(\mathrm{mm}) /$ maximal advancement $(\mathrm{mm})(B)$

\section{Effect of OA on $A H I$}

The mean AHI reduction with OA was $14.3 / \mathrm{h} \pm 7.2\left(\mathrm{p}<10^{-5}\right) .55 .6 \%$ of patients had a $>50 \%$ AHI reduction after OA. The individual absolute and relative reductions of AHI are presented in Figure 3. No patient had an AHI increase with OA (Figure 3).

The other outcomes are shown in Table 1. 


\begin{tabular}{|c|c|c|}
\hline Mean titration consultations number \pm SE $[\min ; \max ]$ & $1.1 \pm 1.0[0 ; 3]$ & \multirow{21}{*}{$\begin{array}{c}\text { Table 1: } \\
\text { population }\end{array}$} \\
\hline Mean absolute advancement \pm SE [min; $\max ](\mathrm{mm})$ & $5.3 \pm 1.5[3 ; 8]$ & \\
\hline Mean relative advancement $\pm \mathrm{SE}[\min ; \max ](\%)$ & $74.8 \pm 17.4[50 ; 125]$ & \\
\hline \multicolumn{2}{|l|}{ AHI: } & \\
\hline Mean AHI before oral appliance \pm SE $[\min ; \max ](/ \mathrm{h})$ & $25.0 \pm 10.4[15 ; 56]$ & \\
\hline \multirow[t]{2}{*}{ Mean AHI after oral appliance \pm SE [min; $\max ](/ \mathrm{h})$} & 11.3 & \\
\hline & $\pm 7.8[0.3 ; 26.1]$ & \\
\hline Mean AHI reduction \pm SE [min; $\max ](\%)$ & $-14.3 \pm 7.2[-31.2 ;-2.5]$ & \\
\hline Residual AHI <5/h N $(\%)$ & $4(22.2 \%)$ & \\
\hline AHI reduction $>50 \%$ and residual $\mathrm{IAH} \leq 10 / \mathrm{h} \mathrm{N}(\%)$ & $5(27.8 \%)$ & \\
\hline$<50 \%$ AHI reduction $\mathrm{N}(\%)$ & $8(44.4 \%)$ & \\
\hline including increase in residual $\mathrm{AHI}$ under OA N(\%) & $0(0 \%)$ & \\
\hline \multicolumn{2}{|l|}{ ODI: } & \\
\hline Mean ODI before oral appliance \pm SE [min; $\max ](/ \mathrm{h})$ & $22.7 \pm 7.5[8.5 ; 36.5]$ & \\
\hline Mean ODI after oral appliance \pm SE [min; $\max ](/ \mathrm{h})$ & $14.2 \pm 8.15[1.1 ; 28.4]$ & \\
\hline \multicolumn{2}{|l|}{ LOS: } & \\
\hline Mean LOS before oral appliance \pm SE [min; $\max ](\%)$ & $80.9 \pm 5.7[72 ; 92]$ & \\
\hline Mean LOS after oral appliance \pm SE [min; $\max ](\%)$ & $80.5 \pm 7.3[63 ; 94]$ & \\
\hline \multicolumn{2}{|l|}{ TB90\%S: } & \\
\hline Mean TB90\%S before oral appliance \pm SE [min; $\max ]$ (min) & $21.8 \pm 23.2[0.3 ; 70]$ & \\
\hline Mean TB90\%S after oral appliance \pm SE [min; $\max ](\min )$ & $14.9 \pm 17.4[0 ; 53]$ & \\
\hline
\end{tabular}
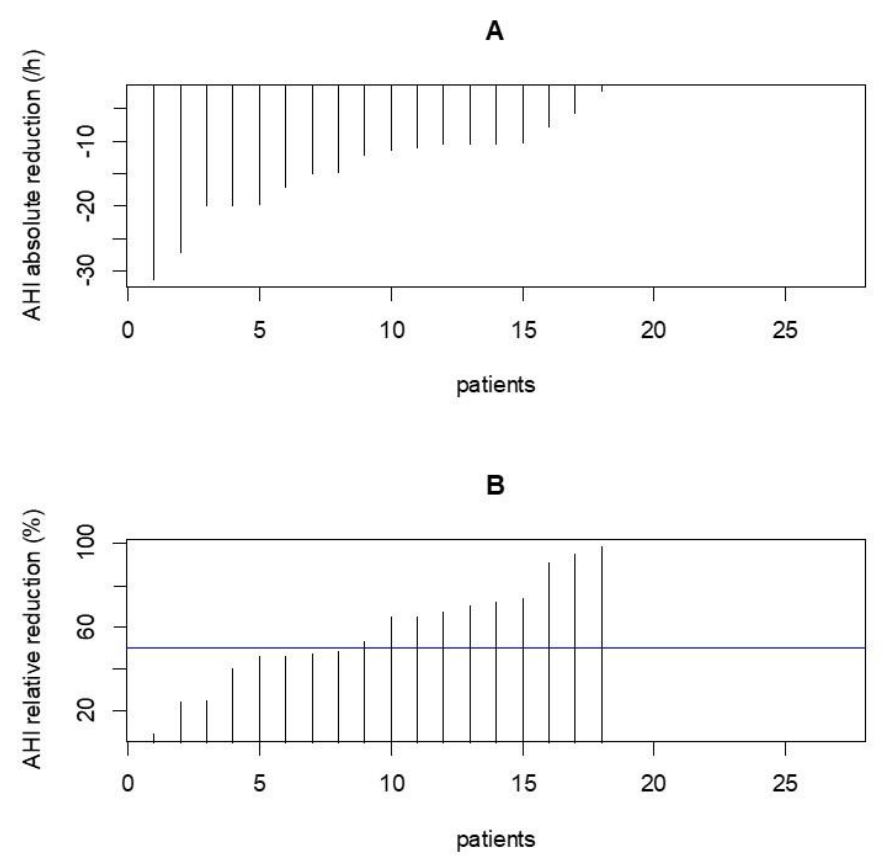

Figure 3: Apnea Hypopnea Index (AHI) reduction.

A: Absolute AHI change $(/ \mathrm{h})$. A positive absolute change means decrease of the AHI after oral appliance; a negative absolute change is increase of the AHI after oral appliance.

B: Relative change of AHI $(\%)=100 \mathrm{x}$ (final AHI-initial AHI) / initial AHI. A positive relative change means a decrease of the AHI after oral appliance, a negative relative change indicates an increase of the IAH after oral appliance

\begin{tabular}{|l|l|l|l|}
\hline & & \multicolumn{2}{|c|}{ Before OA } \\
\hline \multirow{4}{*}{ After OA } & & Moderate OASHS & \multicolumn{2}{|c|}{ Severe OSAHS } \\
\cline { 2 - 5 } & No OSAHS & 4 & 0 \\
\cline { 2 - 5 } & Mild OSAHS & 6 & 2 \\
\cline { 2 - 5 } & Moderate OSAHS & 3 & 2 \\
\hline
\end{tabular}


Severe OSAHS

OA: Oral Appliance, OSAHS: Obstructive Sleep Apnea Hypopnea Syndrome

Table 2 presents changes of OSAHS severity classes.

The absolute and relative changes of AHI per patient are shown in Figure 4. No main characteristics of the patients (age, BMI, initial AHI) had a significant impact on the AHI absolute and relative reduction.
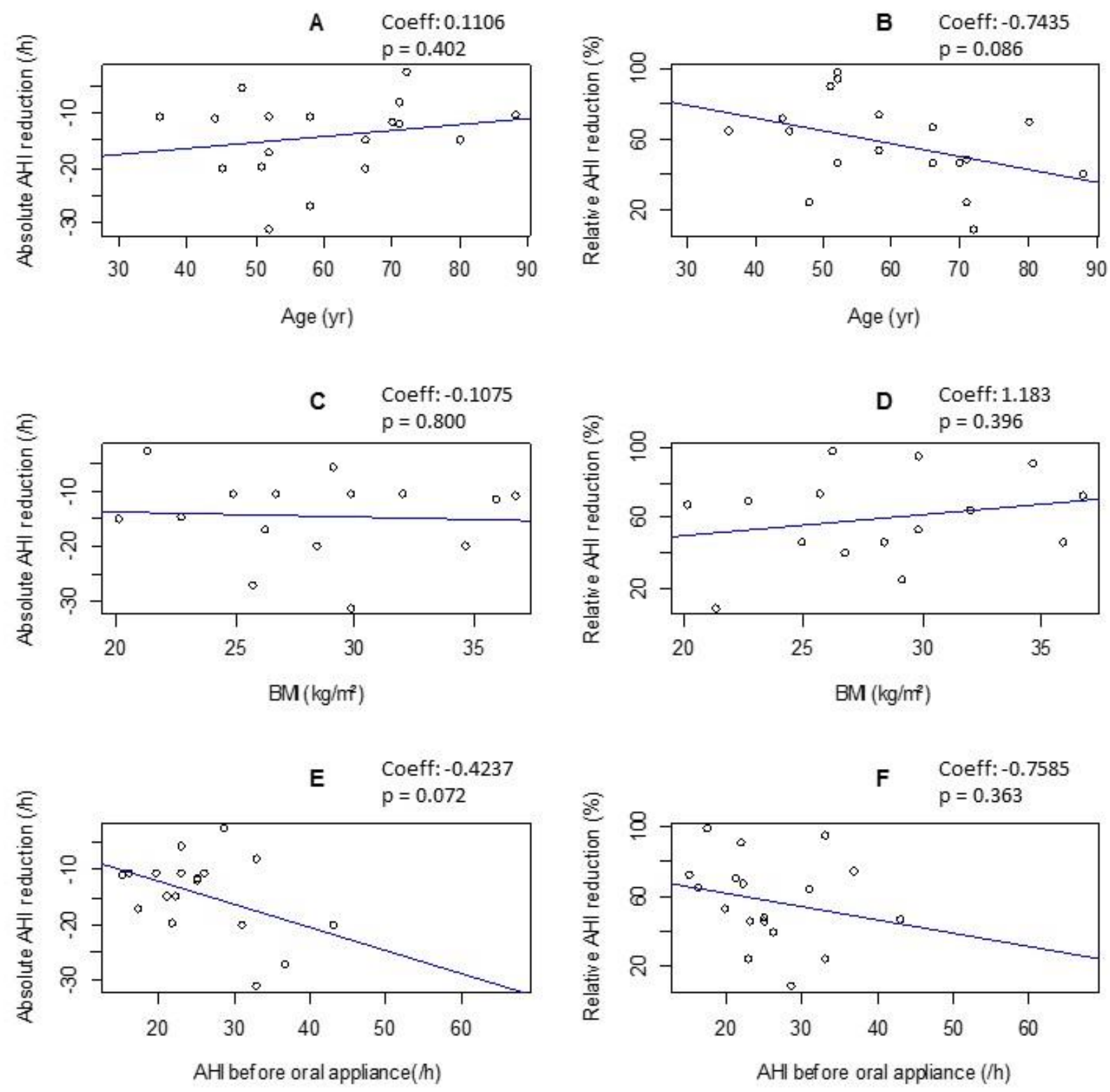

Figure 4:

A: Absolute Apnea Hypopnea Index (AHI) change according to the age

B: Relative AHI change according to the age

C: Absolute AHI change according to the initial body mass index (BMI)

D: Relative AHI change according to the initial BMI

E: Absolute AHI change according to the initial AHI

F: Relative AHI change according to the initial AHI

G: Absolute AHI change according to the absolute advancement 


\section{H: Relative AHI change according to the absolute advancement}

I: Absolute AHI change according to the relative advancement

J: Relative AHI change according to relative advancement

\section{Effect of OA on other vital parameters}

Other outcomes are shown in Table 1.

The mean ODI significantly decreased with OA: -9.3 events/ $h, p=0.021$. The mean LOS did not significantly increase with OA: $+0.13 \%$, $\mathrm{p}=0.9588$. So did the mean TB90S $(-13.2 / \mathrm{h}, \mathrm{p}=0.0967)$.

\section{Compliance and adherence to the $O A$}

Tolerance difficulty (nausea) was reported by one patient (4\%) from the second ENT consultation leading to the discontinuation of the use of OA.

\section{Discussion}

Our study has demonstrated that Somnodent ${ }^{\circledR}$ OA allowed a significant efficacy on AHI (AHI mean decrease of $14.3 / \mathrm{h} \pm 7.2$ and a $50 \%$-AHI reduction rate of $55.4 \%$ ) and on ODI with a mean advancement of $5.3 \mathrm{~mm}$. The efficacy seemed very close to the main studies of Somnodent ${ }^{\circledR}$ OA where the mean AHI decrease was $-16 / \mathrm{h}$ for Mehta et al. [19] (28 patients), $-15 / \mathrm{h}$ for Gotsopoulos et al. [20] (73 patients), $-13 / \mathrm{h}$ (23 patients) for Pitsis et al, $-11.8 / \mathrm{h}$ for $\mathrm{Ng}$ et al. [11] (10 patients). The mean AHI reduction was also similar to our experience in Narval ${ }^{\circledR}$ OA [15] $(-14.9 / \mathrm{h} \pm 11.9 / \mathrm{h}$ and a $50 \%-\mathrm{AHI}$ reduction rate of $65.2 \%)$.

Criteria for OAs efficacy vary according to the studies. The main outcome that we chose to evaluate OA efficacy (AHI decrease ability) is debatable because of its inter- and intra-observer measurement variability and the fact that it is not a clinical parameter. But the impact on AHI is also present on ODI and LOS (more objective but less sensitive parameters) and those parameters are also often retained $[6,15,16,20$ 24].

The OA tolerance was excellent, since only one patient (3.7\%) could not tolerate it, a finding that was consistent with the rates in the literature [7, 25].

Although our study is not comparative, compliance seemed better than the rates reported in the literature in CPAP follow up studies [26, 27] or in studies comparing CPAP and OA [28-30] and comaprable than our experience in Narval ${ }^{\circledR}$ OA [15].

Our study may be criticized because it is retrospective with many patients that did not have a sleep exam control (18.5\%). It must be considered as an evaluation of experience, first step before a comparative study between Narval ${ }^{\circledR}$ OA from Resmed laboratory (Saint-Genis-Laval, France), necessary to calculate the sample size. Indeed our ENT unit has been using the Narval ${ }^{\circledR} \mathrm{OA}$ from for many years. It is an efficient design that is well tolerated by patients $[6,7,15,16,23,31,32]$. We first used the Somnodent ${ }^{\circledR}$ OA to treat patients without teeth and later for any patients with an apparent similar efficacy and tolerance. After having evaluated the efficacy and tolerance of each OA, the next step will be to compare one to another.

\section{Conclusion}

In this study, Somnodent ${ }^{\circledR}$ OA led to a significant AHI and ODI reduction in moderate to severe OSAHS patients. Comparative studies should be performed to determine if a particular type of $\mathrm{OA}$ is more effective or better tolerated than another.

Conflict of Interest: Authors declare that they have no conflict of interest.

Funding: The work was not supported by any fund.
Ethical approval: All applicable international, national, and/or institutional guidelines for the care and use of animals were followed. All procedures performed in studies involving human participants were in accordance with the ethical standards of the institutional and/or national research committee and with the 1964 Helsinki declaration and its later amendments or comparable ethical standards."

Informed consent: For this type of study, formal consent is not required.

\section{Acknowledgements}

To Dr. B Navailles, MD, former head of the ENT Head and Neck surgery department, for developing oral appliances and for the interest he has elicited in all members of his team. RIP.

\section{References}

1. Billiard M, Dauvilliers Y. (2012) Les troubles du sommeil, 2nde édition: Elsevier-Masson.

2. Drager LF, McEvoy RD, Barbe F, Lorenzi-Filho G, Redline S. (2017) Sleep Apnea and Cardiovascular Disease: Lessons From Recent Trials and Need for Team Science. Circulation. 136:1840-50

3. Li W, Xiao L, Hu J. (2013) The comparison of CPAP and oral appliances in treatment of patients with OSA: a systematic review and meta-analysis. Respiratory care. 2013;58:1184-95

4. Lim J, Lasserson TJ, Fleetham J, Wright J. (2006) Oral appliances for obstructive sleep apnoea. Cochrane Database Syst Rev. CD004435

5. Randerath WJ, Verbraecken J, Andreas S, Bettega G, Boudewyns A, Hamans E, et al. (2011) Non-CPAP therapies in obstructive sleep apnoea. Eur Respir J. 37:1000-28

6. Vecchierini MF, Leger D, Laaban JP, Putterman G, Figueredo M, Levy J, et al. (2008) Efficacy and compliance of mandibular repositioning device in obstructive sleep apnea syndrome under a patient-driven protocol of care. Sleep medicine. 9:762-9

7. Vecchierini MF, Attali V, Collet JM, d'Ortho MP, El Chater P, Kerbrat JB, et al. (2016) A custom-made mandibular repositioning device for obstructive sleep apnoea-hypopnoea syndrome: the ORCADES study. Sleep medicine. 19:131-40

8. Santé HAd. (2014) Comment prescrire les dispositifs médicaux de traitement du syndrome d'apnées hypopnées obstructives du sommeil chez l'adulte.

9. Clark GT, Sohn JW, Hong CN. (2000) Treating obstructive sleep apnea and snoring: assessment of an anterior mandibular positioning device. J Am Dent Assoc. 131:765-71

10. Ferguson KA, Cartwright R, Rogers R, Schmidt-Nowara W. (2006) Oral appliances for snoring and obstructive sleep apnea: a review. Sleep. 29:244-62

11. Ng AT, Gotsopoulos H, Qian J, Cistulli PA. (2003) Effect of oral appliance therapy on upper airway collapsibility in obstructive sleep apnea. American journal of respiratory and critical care medicine. 168:238-41

12. Serra-Torres S, Bellot-Arcis C, Montiel-Company JM, MarcoAlgarra J, Almerich-Silla JM. (2016) Effectiveness of mandibular advancement appliances in treating obstructive sleep apnea syndrome: A systematic review. Laryngoscope. 126:50714 
13. Almeida FR, Tsuiki S, Hattori Y, Takei Y, Inoue Y, Lowe AA. (2011) Dose-dependent effects of mandibular protrusion on genioglossus activity in sleep apnoea. Eur Respir J. 37:209-12

14. Buiret G, Chidiac F. (2020) Oral appliances for obstructive sleep apnoea: What can we expect. Rev Mal Respir.

15. Buiret G, Bechara M, Plouin-Gaudon I, Bavozet F, Dancea O, Pujo K, et al. (2021) Oral appliances may be effective in sleep apnea syndrome beyond classical predictive factors. Laryngoscope.

16. Buiret G, Chidiac F. (2020) Long-term oral appliances for moderate to severe sleep apnea syndrome tended to lose efficacy. . J Sleep Med Dis. 6:1112

17. Dieltjens M, Vanderveken OM, Heyning PH, Braem MJ. (2012) Current opinions and clinical practice in the titration of oral appliances in the treatment of sleep-disordered breathing. Sleep medicine reviews. 16:177-85

18. Kushida CA, Morgenthaler TI, Littner MR, Alessi CA, Bailey D, Coleman J, Jr., et al. (2006) Practice parameters for the treatment of snoring and Obstructive Sleep Apnea with oral appliances: an update for 2005. Sleep.29:240-3

19. Mehta A, Qian J, Petocz P, Darendeliler MA, Cistulli PA. (2001) A randomized, controlled study of a mandibular advancement splint for obstructive sleep apnea. American journal of respiratory and critical care medicine. 163:1457-61

20. Gotsopoulos H, Chen C, Qian J, Cistulli PA. (2002) Oral appliance therapy improves symptoms in obstructive sleep apnea: a randomized, controlled trial. American journal of respiratory and critical care medicine. $166: 743-8$

21. Deane SA, Cistulli PA, Ng AT, Zeng B, Petocz P, Darendeliler MA. (2009) Comparison of mandibular advancement splint and tongue stabilizing device in obstructive sleep apnea: a randomized controlled trial. Sleep. 32:648-53

22. Doff MH, Hoekema A, Wijkstra PJ, van der Hoeven JH, Huddleston Slater JJ, de Bont LG, et al. (2013) Oral appliance versus continuous positive airway pressure in obstructive sleep apnea syndrome: a 2-year follow-up. Sleep. 36:1289-96
23. Hamoda MM, Kohzuka Y, Almeida FR. (2018) Oral Appliances for the Management of OSA: An Updated Review of the Literature. Chest. 153:544-53

24. Marklund M, Verbraecken J, Randerath W. (2012) Non-CPAP therapies in obstructive sleep apnoea: mandibular advancement device therapy. Eur Respir J. 39:1241-7

25. Hoffstein V. (2007) Review of oral appliances for treatment of sleep-disordered breathing. Sleep \& breathing Schlaf \& Atmung. 11:1-22

26. Sawyer AM, Gooneratne NS, Marcus CL, Ofer D, Richards KC, Weaver TE. (2011) A systematic review of CPAP adherence across age groups: clinical and empiric insights for developing CPAP adherence interventions. Sleep medicine reviews. 15:34356

27. Engleman HM, Wild MR. (2003) Improving CPAP use by patients with the sleep apnoea/hypopnoea syndrome (SAHS). Sleep medicine reviews. 7:81-99

28. Barnes M, McEvoy RD, Banks S, Tarquinio N, Murray CG, Vowles N, et al. (2004) Efficacy of positive airway pressure and oral appliance in mild to moderate obstructive sleep apnea. American journal of respiratory and critical care medicine. 170:656-64

29. Lam B, Sam K, Mok WY, Cheung MT, Fong DY, Lam JC, et al. (2007) Randomised study of three non-surgical treatments in mild to moderate obstructive sleep apnoea. Thorax. 62:354-9

30. Randerath WJ, Heise M, Hinz R, Ruehle KH. (2002) An individually adjustable oral appliance vs continuous positive airway pressure in mild-to-moderate obstructive sleep apnea syndrome. Chest. 122:569-75

31. Attali V, Chaumereuil C, Arnulf I, Golmard JL, Tordjman F, Morin L, et al. (2016) Predictors of long-term effectiveness to mandibular repositioning device treatment in obstructive sleep apnea patients after 1000 days. Sleep medicine. 27-28:107-14

32. Dieltjens M, Vanderveken OM, Hamans E, Verbraecken JA, Wouters K, Willemen M, et al. (2013) Treatment of obstructive sleep apnea using a custom-made titratable duobloc oral appliance: a prospective clinical study. Sleep \& breathing Schlaf \& Atmung.17:565-72. 


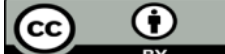

This work is licensed under Creative Commons Attribution 4.0 License

To Submit Your Article Click Here: Submit Manuscript

DOI: $10.31579 / 2692-9562 / 037$
Ready to submit your research? Choose Auctores and benefit from:

* fast, convenient online submission

* rigorous peer review by experienced research in your field

* rapid publication on acceptance

* authors retain copyrights

* unique DOI for all articles

* immediate, unrestricted online access

At Auctores, research is always in progress.

Learn more https://auctoresonline.org/journals/journal-of-clinicalotorhinolaryngology 